\title{
The History and Current Direction of Rangeland Management in Turkey
}

\author{
By Ali Koc, Walter H. Schacht, and H. Ibrahim Erkovan
}

\section{On the Ground}

- Turkey is a country with many urban centers (Istanbul has 15 million people) and with a high gross national product (16th in the world). More than one-third of the country is rangeland and livestock production accounts for at least 30\% of agricultural income.

- Rangelands and livestock production on rangelands historically have been at the center of Turkish society, economy, and culture. Roots of many Turkish range management practices can be traced back to the steppes culture of central Asia in 2500 BC.

- The government established strict policies and regulations on the communal rangelands allocated to each community by the central government. The grazing management regulations were based on strategies to ensure that 1) stocking rates did not exceed carrying capacity, 2) timing of grazing was in balance with seasonal conditions, and 3) grazing units were periodically deferred.

- The composition and productivity of Turkeys rangelands have degraded considerably since the early 1900 s with an increasing density of humans and their livestock on grazing lands and an abandonment of the traditional policies and structure regulating grazing of rangelands.

- The Rangeland Act of 1998 gave the Turkish government authority to regulate the grazing season, carrying capacity, and rangeland development and use. Consideration of agrarian reform measures is at the center of revitalizing the publicly owned rangelands in Turkey.

Keywords: Turkey, Anatolia, Thrace, traditional knowledge, tore, communal rangeland, rangeland degradation.

Rangelands 37(1):39-46

doi: $10.1016 /$ j.rala.2014.12.005

(C) 2015 The Society for Range Management

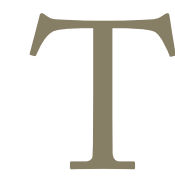

urkey lies like a bridge between Europe and Asia. Anatolia is the Asian part of Turkey and makes up $97 \%$ of country's surface area. Thrace is considered the European component and comprises 3\% of country's surface area. Turkey borders Greece and Bulgaria in the west (European part), Syria and Iraq in the south, and Iran, Azerbaijan (Naxcivan Autonomous Republic), Armenia, and Georgia in the east (Asian part) (Fig. 1). The principal land uses of Turkey's 77.8 million ha are 21.4 million ha of field crops; 0.8 million ha of vegetables; 2.2 million ha of vine, fruit, olive, hazelnut and other agricultural trees; 22.9 million ha of rangelands (mostly dry grasslands and grass/shrublands); 1.4 million ha of meadows; 15.1 million ha forests; and 14.0 million ha of other areas, mainly water, settlements/cities, and barren areas, including degraded rangelands. ${ }^{1}$

\section{Grazing History of Anatolia}

Turkey's gross national income is $\$ 772$ billion with $\$ 70$ billion coming from agriculture. Animal husbandry accounts for about $30 \%$ of agricultural income. The country has 11.4 million large (mostly cattle) and 27 million small livestock (mostly sheep and goats). ${ }^{2}$

All small and a vast majority of large livestock are raised extensively and depend on rangelands and harvested residues in agricultural areas for feed. Rangelands are critically important to livestock production, especially during the growing season when other sources of forage are scarce. There are intensively managed livestock enterprises, especially dairy farms, that are not dependent on rangeland and are located near cities in the western and central parts of the country.

Rangelands and livestock production on rangelands historically have been at the center of Turkish society, economy, and culture. Roots of many Turkish range management practices can be traced back to the steppes culture of central Asia. The first organized government of the Turks was called Cou and was established in $2500 \mathrm{BC}$ on the steppes of Central Asia. Because Turkish culture was based on 


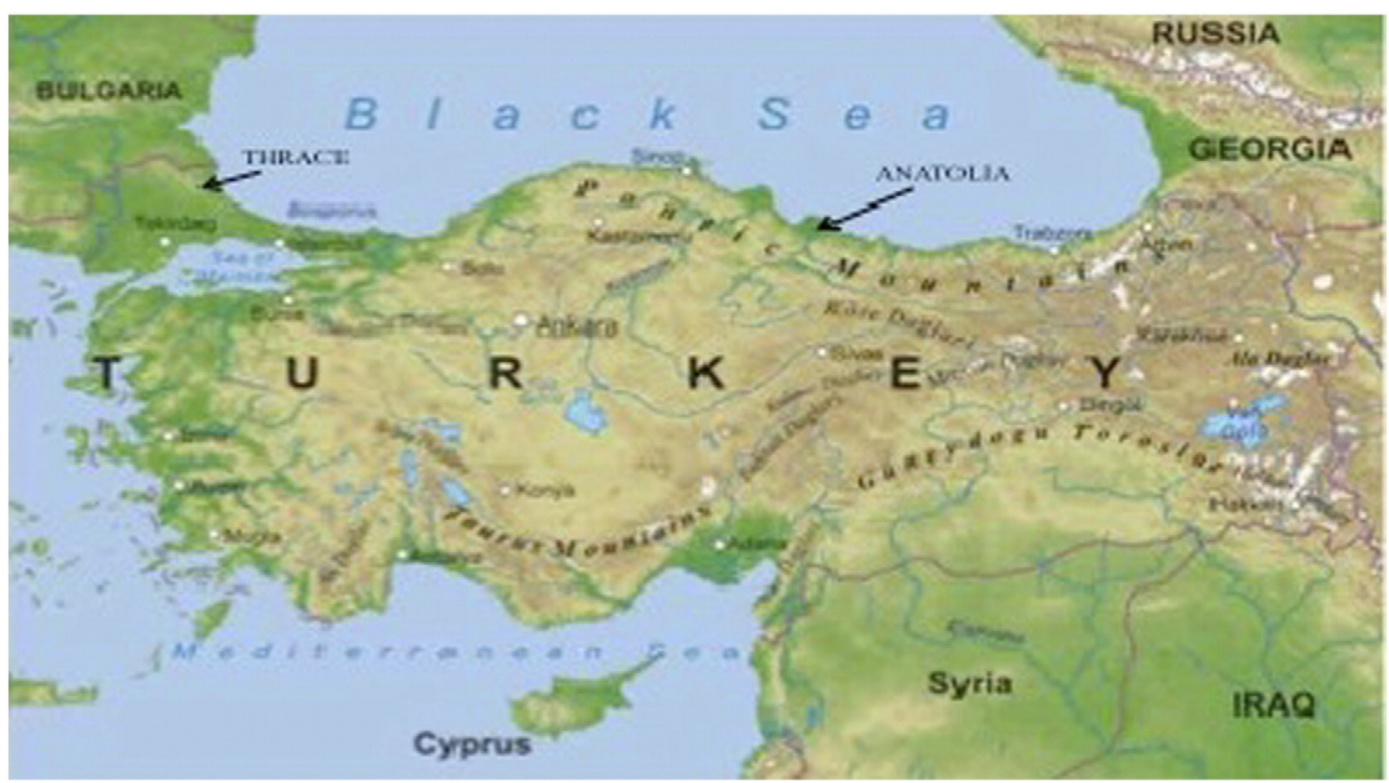

Figure 1. Geomorphologic map of Turkey. (freeworldmaps.net. Turkey-map.jpg).

livestock production, the most important ministry of the government was animal husbandry. The government established strict policies and regulations related to animal raising and grazing management on the communal lands allocated to each community by the central government. ${ }^{3}$ Tore, which was the traditional oral law governing both economic and social life in the community, had a crucial role in steppe communities and culture. (Even today, some disagreements among rural communities are solved by the rule of "tore" before going to court.) Grazing season, grazing intensity, and herd management practices were set and enforced based on tore rules. In a sense, the strict tore rules focused on proper resource management and avoided the tragedy of the commons seen in many other societies throughout the world. ${ }^{4}$

The tore was taken with the Turks as they moved to modern-day Turkey where they became the dominant people in Anatolia by AD 1000. The rigid tore rules concerning resource and grazing management remained in place through the Anatolian Seljuk (AD1000-1243 AD) and Ottoman (AD 1299-1922) eras. In the mountainous Anatolia region, the Turks practiced transhumance and small communities (oba) moved seasonally from lowlands to highlands as weather and forage conditions dictated. Transhumance was a lifestyle for the Turks rather than solely an animal production activity. Every transhumant had a simple place (house or tent) for living, processing milk and other livestock products, and making handcrafts, such as carpet and leather products. Because plant growth and grazing conditions changed over the range of grazing land types of most communities, the principal tore rules concerning grazing were focused on its timing or season. The central government had regulation authority on all lands in Anatolia. Each community was allocated a tract of land from the central government that represented a route by which they would take their livestock from lowland to highland through the four seasons. Grazing began in spring on half of the lowlands with readiness based on plant height of the mid to tall grasses. Grazing of an area could not begin until the major forage plants were a span in height (distance from the thumb to little finger of an open hand; about $20 \mathrm{~cm}$ ). ${ }^{5}$ The other half of the lowlands was excluded from grazing until the major forage plant species reached the flowering stage in early summer. Livestock were moved to highlands as plant height of the short to mid grasses of the higher-elevation grazing lands reached the four to five finger height (distance from thumb to little finger of a closed hand; about $10 \mathrm{~cm}$ ). During the winter, livestock were either fed hay in barns or grazed lowlands. Movement was the law of the land and season-long or year-round grazing of a single management unit was not allowed.

The central government did not allow communities to degrade their rangelands; grazing capacity was identified and stocking rates strictly enforced. A community would need to find other land when animal numbers exceeded the grazing capacity of the community's allotment. Members of one community could not use the grazing land of another; instead, owners of excess animals would need to move to areas outside of community allotments. The strict enforcement of the tore resulted in Turkish tribes moving to other parts of Asia, Europe, and northern Africa, including the Yakuts tribe to Siberia, the Gagaus tribe to Ukraine, and other tribes to Rumania, Bulgaria, Greece, and Hungary.

Herding was a recognized and respectable profession. Education of herders was a priority within communities and focused on range and herd management and animal welfare. Each herder specialized by animal species, including sheep, goats, cattle, and horses. Each community had a general director of herding who was responsible for grazing land regulation and general herd control, as well as for coordination between the community and the central government.

Although there are no scientific records, it has been argued that there was a steady state between plant production and herbivory on the grazing lands managed for millennia by the 
Turks on the rangelands of central Asia and Anatolia. These anthropogenic rangelands likely were dominated by a mixture of native tall, mid, and short grasses and shrubs. ${ }^{6}$ Land management changed significantly in the late 1800s and early 1900s with the weakening and then collapse of the Ottoman Empire, the transition to the establishment of the Republic of Turkey, and the unrest associated with World War I. During this time, the central government lost much of its authority related to land management and the human population structure changed significantly with a huge immigration of people from such areas as the Balkans. The ancient tore laws were no longer applied consistently and common lands were used with very few rules. Rangelands dominated by mixed grasses and shrubs gave way to short grasses, primarily sheep fescue (Festuca ovina L.), and unpalatable shrubs.

\section{Republic of Turkey Era}

After establishing the Republic of Turkey in 1923, the government relied on agriculture to improve the collapsed national economy because there were no industrial sectors in the country. Rangelands remained relatively productive during the first half of the 20th century because the rangeland base was large and livestock numbers were still largely in balance with the forage resources. Until the 1950s, there were about 40 to 45 million ha of rangeland and 10 million large stock units ( $\mathrm{LU}=$ animal unit or a $450 \mathrm{~kg}$ nonlactating cow) resulting in $4.25 \mathrm{ha} / \mathrm{LU}$ on a nationwide basis ${ }^{7}$ (Table 1 ). Assuming a 6-month grazing season on rangeland, the stocking rate would be about $1.42 \mathrm{AUM} / \mathrm{ha}$ (0.57 AUM/ acre). Crop farming (particularly small grain) increased rapidly in the 1950s because of farm mechanization resulting in conversion of millions of ha of rangeland to crop land. With a concomitant increase in livestock numbers in the 1950s,

Table 1. Changes in total rangeland area, number in large stock units (LU; mostly cattle), and rangeland area per large stock units during the Republic of Turkey era.

\begin{tabular}{|l|l|l|l|}
\hline Years & $\begin{array}{l}\text { Rangeland } \\
\text { Area (millions } \\
\text { of ha) }\end{array}$ & $\begin{array}{l}\text { Livestock } \\
\text { Number } \\
\text { (millions } \\
\text { of LU) }\end{array}$ & $\begin{array}{l}\text { Rangeland } \\
\text { Area/LU } \\
\text { (ha) }\end{array}$ \\
\hline 1930 & 44.5 & 10.0 & 4.55 \\
\hline 1940 & 44.3 & 10.2 & 4.36 \\
\hline 1950 & 37.8 & 10.5 & 3.60 \\
\hline 1960 & 28.6 & 13.2 & 2.17 \\
\hline 1970 & 26.1 & 13.2 & 1.98 \\
\hline 1980 & 21.7 & 17.5 & 1.24 \\
\hline 1990 & 21.7 & 14.5 & 1.50 \\
\hline 2000 & 14.6 & 11.2 & 1.30 \\
\hline 2010 & 14.6 & 10.1 & 1.45 \\
\hline LU: $500 \mathrm{~kg}$ live weight & & \\
\hline
\end{tabular}

LU: $500 \mathrm{~kg}$ live weight between 1950 and 1960. By the 1980s, overgrazing and rangeland degradation became a serious concern with most rangelands overstocked by two- to threefold and $90 \%$ of the rangelands subject to erosion.

After 1980, the government classified 14 million ha of Turkey's agricultural lands as undefined (i.e., highly degraded) areas and not eligible for grazing or cultivation. A vast majority of these undefined areas were comprised of denuded rangeland. Finally, with continued degradation of rangelands used for grazing, the Turkey parliament in 1998 passed the Rangeland Act, which gave the central government the authority to regulate grazing season, carrying capacity, rangeland development, and other measures to control rangeland use. However, the Rangeland Act has not been enforced because rangeland assignment, restriction, and determination studies have not been completed. Overgrazing is still the major problem as grazing begins as soon as snowmelt occurs and continues until grazing lands are covered by snow again. The tore and its traditional knowledge relative to management of grazing lands are no longer recognized as critical to the sustained use of rangeland resources. The grazing management regulations of the tore were based on strategies developed and implemented to ensure that 1) stocking rates did not exceed carrying capacity, 2) timing of grazing was in balance with seasonal conditions, and 3) grazing units were periodically deferred. This traditional knowledge, and associated organizational structure and policy, that allowed for domestic livestock grazing for 4,500 years should be considered for incorporation into new policy and practices associated with livestock grazing of Turkish rangelands.

In the current Republic of Turkey era, grazing lands are allocated to villages and each villager has a grazing right to the village allotment. Livestock owners in many of these villages still practice transhumance. Some groups in eastern and central Turkey use a temporary settlement other than their permanent village; whereas, groups in the Taurus Mountains of the Mediterranean Region use as many as eight temporary settlements over a route of $250 \mathrm{~km}$ originally assigned to them by an Ottoman decree. Regardless of the transhumant system used, there is no effective means of controlling stocking rate because there are no limits to the number of villagers who can own livestock or to the number of livestock that a villager can own. Livestock owners on grazing lands are still too numerous and herd size so small, an average of 10 cattle per enterprise, that income is far less than what is needed to support a household unit. With individuals struggling to earn a living by grazing livestock, resources are not available at the individual or village levels to invest in improved management practices on rangelands. This scenario has created challenges for government policymakers, advisors, and the livestock production industry.

\section{Climate Zones and Rangeland Types}

In Anatolia, mountain ranges extend from west to east, running parallel to the north and south coasts. Elevation increases gradually 


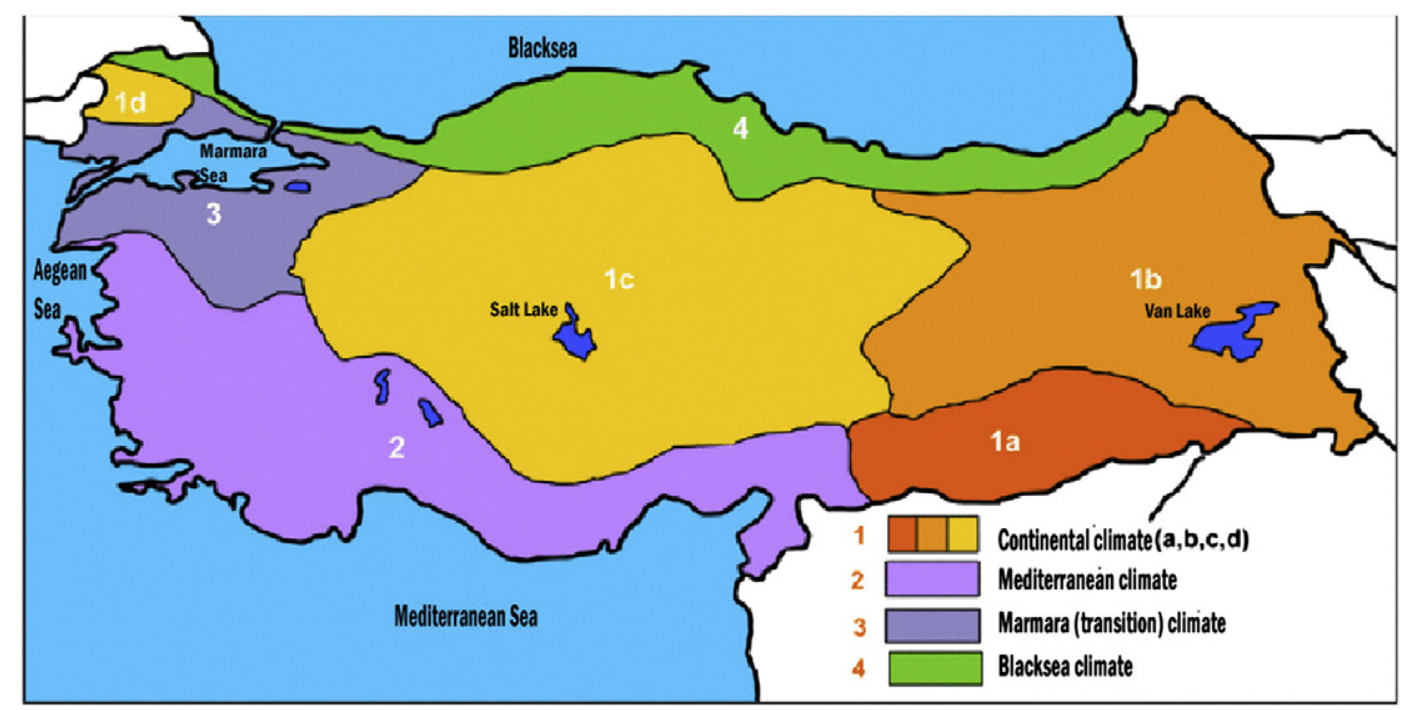

Figure 2. Climate zones of Turkey. (in-reverse-gear.com. Turkey_climate_map.gif).

from the west to the east. As a result of this geomorphologic feature, different climatic zones occur in the country (Fig. 2). ${ }^{8}$ These differences cause different rangeland types and lead to variable range practices. Here we describe the four major climate zones and their different range types and practices.

\section{Mediterranean Climate Zone}

The Mediterranean climate zone covers the coastal areas of the Mediterranean and Aegean seas to the Taurus Mountain range, which lies parallel to the Mediterranean Sea coast (Fig. 2). The climate is characterized by a mild, rainy winter and a hot, dry summer with annual precipitation ranging from $600 \mathrm{~mm}$ to $1,100 \mathrm{~mm}$. Chaparral vegetation is the dominant natural plant cover from sea level up to an $800 \mathrm{~m}$ elevation and drought-resistant coniferous forest is the primary vegetation type from $800 \mathrm{~m}$ to $1,800 \mathrm{~m}$ elevation. Above $1,800 \mathrm{~m}$, there are alpine rangelands in the Taurus Mountains and mountains in the Aegean region. Rugged topography and shallow soils restrict cultivation in much of the zone. Grazing lands cover about 10.6 million ha, of which 8.3 million ha is shrublands or chaparral. Small ruminants, especially meat goats, are the principal grazing animals, although cattle production is common in forest gaps, alpine rangelands, and subirrigated lowlands. Transhumance is common with some transhumant groups moving as far as $250 \mathrm{~km}$ from their permanent settlements along the coast. They move with their herd from

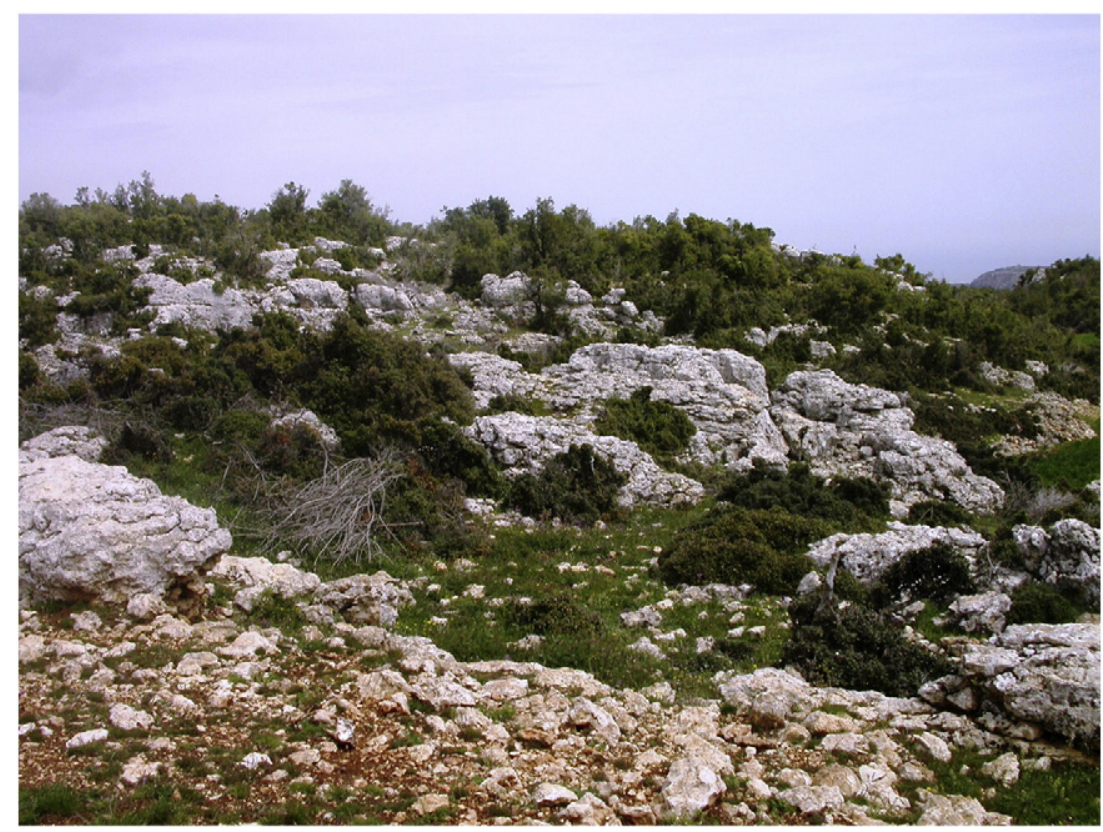

Figure 3. Shrublands on Taurus Mountain in the Mediterranean climate zone. 


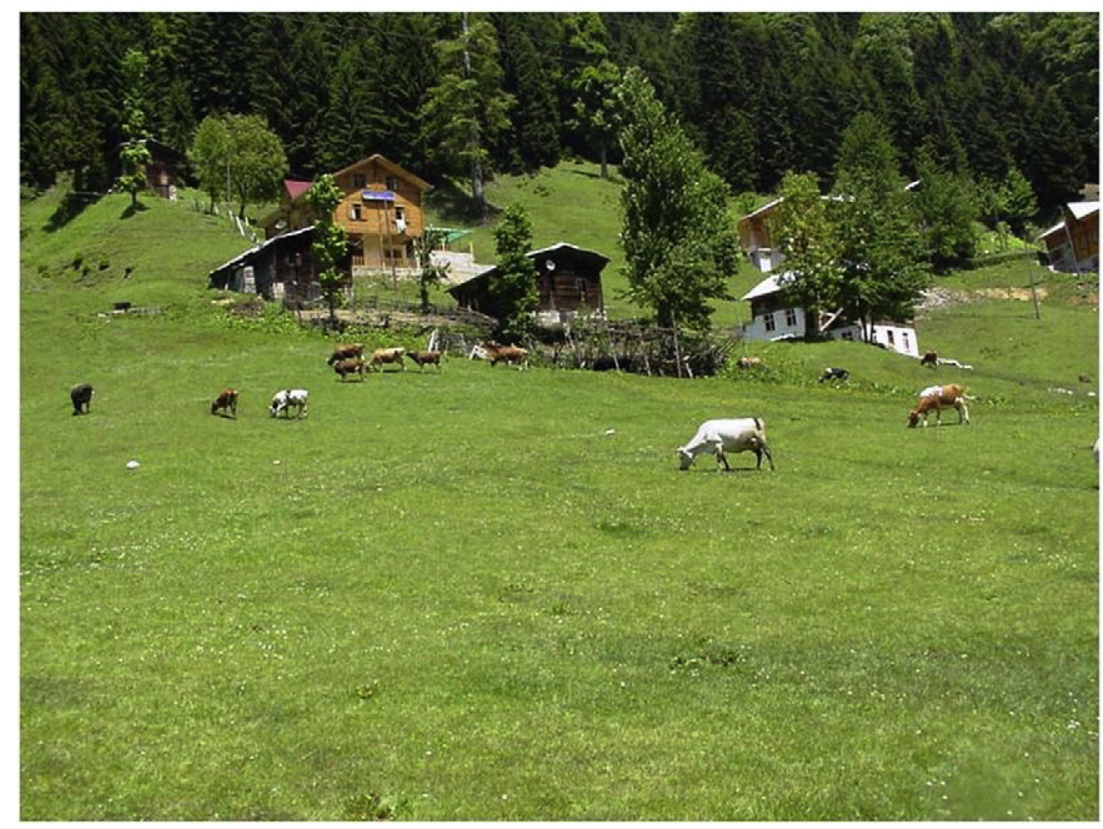

Figure 4. Forest gap rangelands in Artvin province in the eastern part of the Black Sea climate zone.

the coast in the spring and reach the summit of Taurus Mountains in mid-summer; thereafter, they take their herds to northern aspect of the mountains and continue to central Anatolia. With the onset of the autumn rains, they return to their permanent settlements by late autumn. Each transhumant group uses the same route and grazing lands each year as dictated by their grazing rights. Shrubs provide forage for animals during much of the long, dry summer (Fig. 3) because herbaceous plants have died or senesced.

\section{Black Sea Climate Zone}

The Black Sea climate zone is a narrow west-to-east strip between the Black Sea coast and the ridge of the Black Sea Mountains (Fig. 2). Annual precipitation is about $550 \mathrm{~mm}$ in the west and gradually increases to $2,200 \mathrm{~mm}$ in the east. Forests are the principal vegetation cover up to $1600 \mathrm{~m}$, with coniferous forests in the west, mixed coniferous and deciduous forests in the central area, and deciduous forests in the rugged east. Maximum elevations range from $1,000 \mathrm{~m}$ in the west to $2,500 \mathrm{~m}$ in the east.

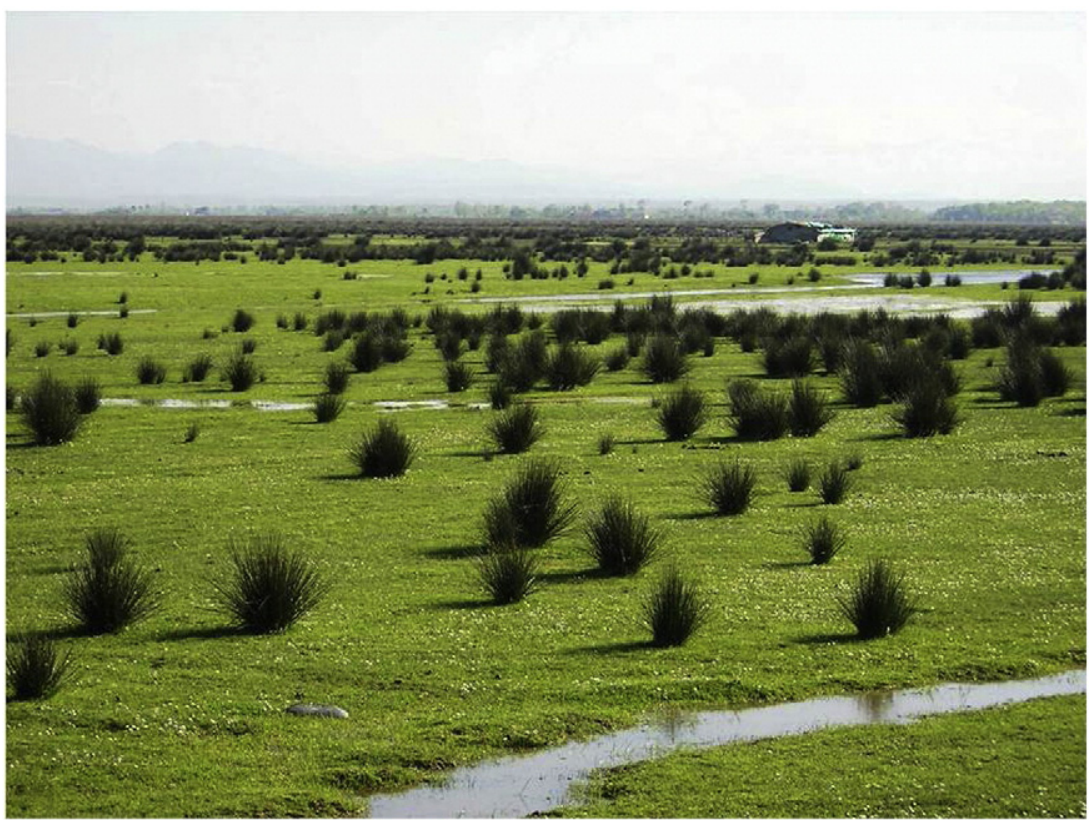

Figure 5. Subirrigated rangelands on Red River Delta in Bafra Plain, Samsun Province in the Black Sea climate zone. 


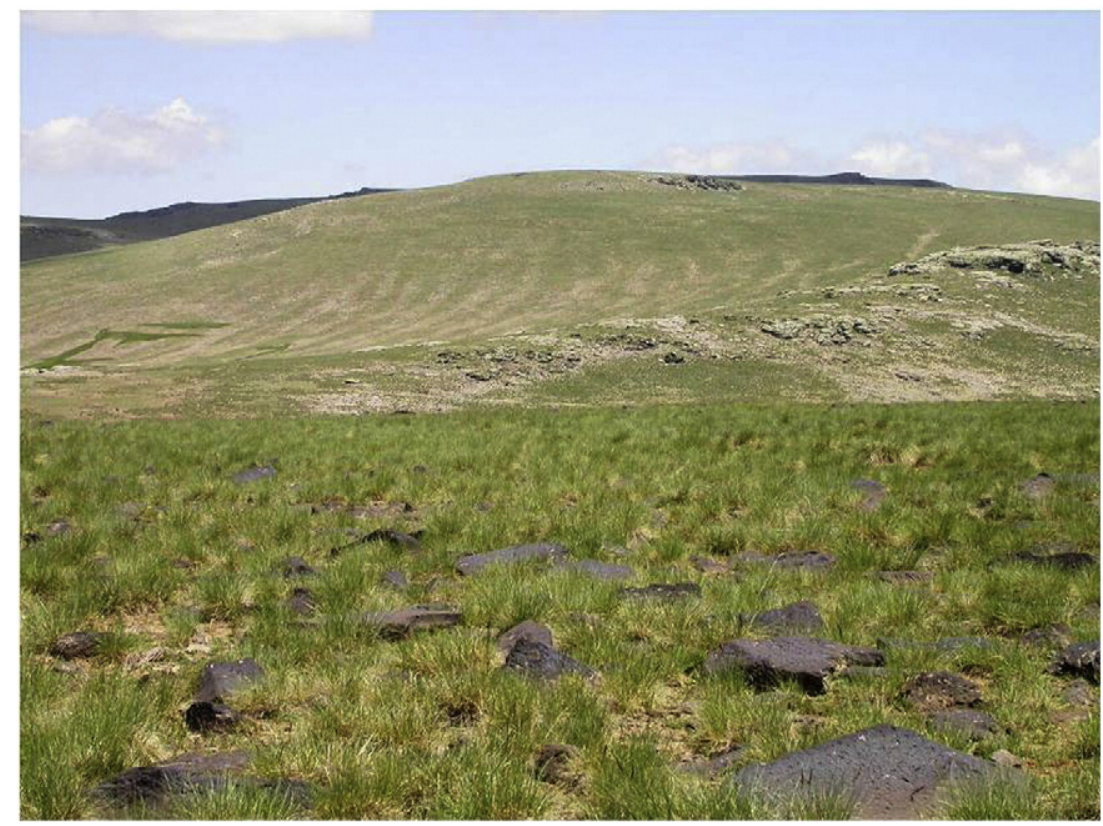

Figure 6. Highland dry steppe in southeastern Anatolia.

Rangelands cover about 1.3 million ha and are largely restricted to forest gaps and the large expanses of alpine areas above $1600 \mathrm{~m}$. Small ruminants, especially sheep, are the principal livestock in the west and dairy and beef cattle are more common in the east. Transhumance is also common with livestock owners from northern Anatolia moving into the forest gaps of the Black Sea highlands in the summer. These people live in picturesque temporary settlements surrounded by productive, diverse rangeland (Fig. 4). Subirrigated rangelands are located in coastal areas, particularly on deltas of the Green and Red rivers. Salinity is a significant problem in these rangelands; salt tolerant plants, for example, Bermuda grass (Cynodon dactylon L.), birdsfoot trefoil (Lotus corniculatus L.), foxtails (Alopecurus spp.), and rushes (Juncus spp.), are common plants (Fig. 5). Rushes have invaded these subirrigated areas as a result of overgrazing. Water buffalo production is common on these rangelands because they efficiently use rushes. Water buffalo milk products also are popular, including skimmed milk and yogurt.

\section{Marmara Transition Zone}

Marmara region has a transition climate between the Mediterranean Sea and Black Sea climates (Fig. 2). Annual precipitation is about $600 \mathrm{~mm}$ and is nearly evenly distributed throughout the year, although plant water stress is usually high in late July and August because of hot weather. Except for the Uludag and Kazdaglari mountains in the southern part of the region, topography is flat to rolling hills. Flat areas are either cultivated or covered by forest although there are some subirrigated areas. Alpine rangelands and forest gaps are also common in the Uludag and Kazdaglari mountains. Total rangeland coverage is about 1 million ha. Cattle and water buffalo grazing are common on subirrigated rangelands and cattle are the dominant livestock on forest gap grazing lands. Sheep grazing is the principal land use on the rangelands of the Uludag Mountains, whereas goat production is common in the Kazdaglari Mountains.

\section{Continental Climate Zone}

The continental climate zone covers more than half of the country (Fig. 2). Natural vegetation and climatic pattern show a certain extent of variation among subdivisions of the continental climate zone. We describe the general characteristics of these subdivisions here.

Southeastern Anatolia Subdivision. This southeastern Anatolia climate subdivision is in southeastern Turkey on the high plains (elevation of 500-1,000 m) that extend into Syria (Fig. 2). Average annual precipitation is about $500 \mathrm{~mm}$, with most falling in autumn to spring. There is almost no precipitation during the hot summer (daily high temperatures greater than $40^{\circ} \mathrm{C}$ in July and August). Summer precipitation shortage restricts plant production on both agricultural lands and rangelands. The 1 million ha of rangeland is mostly degraded because this subclimatic zone is in the "fertile crescent," at the heart of a series of civilization centers that have intensively used the land for multiple millennia. Although perennial, warm-season grasses likely once covered the high plains, a sparse cover of mostly annual grasses and invasive perennial forbs are there now (Fig. 6).

Small ruminant grazing is the main rangeland use. Forage production changes from year to year because of annual variability in precipitation. Forage quality drops sharply as temperature increases and precipitation ceases during the summer. Most sheep are transported by truck to the eastern Anatolia highlands in early summer. Transported animals return to the region after the first rainfalls of autumn where they graze until the following summer. 
Eastern Anatolia Subdivision. The eastern Anatolia region in east central Turkey is a high plateau (>\&thinsp1500 m) with mountain ranges commonly at $2,000 \mathrm{~m}$ and greater (Mount Ararat is $5137 \mathrm{~m}$; Fig. 2). Average annual precipitation is between $400 \mathrm{~mm}$ and $650 \mathrm{~mm}$ and most of it falls from autumn through spring. Vegetation cover of the region's 6 million ha of rangeland is dominated by cool-season grasses that are dormant during the summer, especially in August and early September. Mountain steppe with dense cover of short grasses, mainly sheep fescue, and some legumes (such as Medicago spp., Trifolium spp., and Onobrychis spp.) is the dominant rangeland type in the region. Snow cover is from mid-November to late March, limiting dormant-season grazing to south-facing slopes.

Livestock production is the main agricultural enterprise in the region because climate conditions restrict field crop options. Also, much of the cropland is used for forage production because of the huge need for stored forages for the long winter, which can extend to 200 days in many parts of the region. Transhumance is common as people move their livestock to the highlands during the summer from lower elevation areas in eastern Anatolia and surrounding areas, especially southeastern Anatolia. Grazing season in the highlands is limited to about 75 days (late June to early September). Cattle and sheep are the principal livestock species, although sheep numbers have decreased tremendously in the past several decades because of declining exports to neighboring countries.

Central Anatolia Subdivision. Central Anatolia (Fig. 2) covers 18.5 million ha and has about 6 million ha of rangeland. Elevation of the rangelands is between $500 \mathrm{~m}$ and $1,500 \mathrm{~m}$, although there are mountainous areas that are classified as rangeland. Average annual precipitation is about $400 \mathrm{~mm}$, most of which falls from autumn through spring. Summer precipitation shortage restricts plant production in both agricultural lands and rangelands.

Dry steppes cover large areas in the region, especially on flat areas with shallow soil and rugged topography. Sparse plant cover with short and drought-resistant species such as sheep fescue, annual grasses, forbs, and some shrubs are common on the steppes. These rangeland conditions are not suitable for cattle production; therefore, small ruminant husbandry, especially sheep, is the main rangeland use in the region. Plants initiate growth in March and reach maturity or stop growth by late July because of dry conditions. At this time, livestock producers use any of a number of options: 1) livestock continue to graze the remaining dry herbaceous plants and evergreen shrubs on the steppes; 2) livestock producers can move their animals to rangelands in the mountains for the summer; 3) cereal grain fields are grazed following harvest in mid-July. Rangelands commonly are invaded by Peganum spp. and Genista spp. because of improper grazing management practices over the past century. Although these plants are considered undesirable forage species, they have a crucial role with respect to erosion control.

\section{Rangeland Management in Turkey}

With the transition from the Ottoman Empire to the Republic of Turkey in the early 20th century, grazing regulations associated with the tore were largely lost and nonregulated grazing of rangelands became the norm. The increasing stocking rates on rangeland through the 20th century and the Turkish government's act of condemning 15.4 million ha of rangeland and cropland in the 1980s are just a few of the indicators of the poor condition of Turkish rangelands. The Rangeland Act of 1998 gave the central government the authority to regulate grazing season, carrying capacity, rangeland development, and other measures to control rangeland use. The National Range Management and Rehabilitation Project was conducted from 2007 to 2011 as part of the Rangeland Act. Rangeland condition and health, common plant species and their distribution, and season of grazing of the major rangeland types were determined and mapped using geographic information systems and satellite imaginary. This information was the basis for development of improvement and management recommendations for the major rangeland types. Range improvement and development projects planned and implemented by local range management offices initially showed promise but most have failed because grazing pressure could not be controlled.

All rangelands in Turkey are public property with grazing rights allocated to communities and the rangelands within their jurisdictions. All members of a community have access to the community's rangelands and numbers of livestock are not restricted. The government of Turkey, through the Ministry of Agriculture, has the authority to regulate stocking rates through the Rangeland Act of 1998 but very little action has been taken. There appears to be a need to re-examine grazing policies and regulations on the communal rangelands of Turkey. Further degradation of Turkish rangelands cannot be allowed and range management practices that are relevant to the communal rangelands of Turkey must be developed and implemented. The degradation of Turkey's land resources has given rise to a discussion concerning agrarian reform and land ownership and allocation. Major questions include whether rangeland ownership should be converted from the public (communal) to the private sector (individual) and whether long-term land leases to individuals should be considered. The reasoning behind these proposals is that individuals will better manage rangelands for sustained use and that the Ministry of Agriculture can influence land management more effectively through individuals than communities. Regardless of the politically related issues of agrarian reform and land ownership, there are a number of other rangeland issues that need to be addressed.

Rangeland management and development in Turkey is based on the Clementsian plant succession or climax model. Many of the Clementsian model principles and associated assessment procedures are not relevant to the rangeland situation in Turkey. A model is needed that can guide managers and advisors in managing and assessing Turkey's rangelands - rangelands that are degraded and driven by unique sets of environmental and anthropogenic factors. The 
Ministry of Agriculture and the range profession is in the midst of moving from the plant succession model to the stateand-transition model. A major effort is underway within the Ministry of Agriculture to identify ecological sites and associated plant communities, and to develop ecological site descriptions. A principal component of the ecological site descriptions would be to identify stable states and transitions between states and associated carrying capacity and grazing practices. The rangeland health approach used in the United States also is viewed as an important assessment tool. Rangeland health could provide the information needed to evaluate rangelands and effectiveness of rangeland programs administered by the Ministry of Agriculture through the Rangeland Act of 1998.

Turkish rangeland scientists and managers also are committed to maintaining the biodiversity on their rangelands. With Turkey located at the intersection of Asia, Europe, and Africa, plant diversity is very high and Turkish rangelands are the source of forage plants and cereal crops used throughout the world. Plant breeding programs continue to use Turkey as a source of plant material.

Turkish traditional range management practices and systems were adapted to local conditions and critical in the sustained use of rangeland resources for millennia. Current managers, advisors, and policymakers should take these timeproven practices and systems into account and integrate them into their management strategies and government programs.
Consideration of traditional knowledge can help rebuild a sustainable system for the use of rangelands of Turkey.

\section{References}

1. Turkish Statistical Institute. 2010. Turkey's statistical yearbook. Available at: www.tuik.gov.tr. Accessed 15 December 2014.

2. Turkish Statistical Institute. 2012. Turkey's statistical yearbook. Available at: www.tuik.gov.tr. Accessed 15 December 2014.

3. Kafescioglu, I. 1992. Culture and organization. Handbook of Turkish World. Turkish Culture Research Institute Publ. No: 121 (1, A-23), p. 454.

4. Hardin, G. 1968. The tragedy of commons. Science 162:1243-1248.

5. Gokkus, N., AND A. GoKkUs. 2007. Steppe culture in Turks and rangeland animal husbandry. Proceedings of the Seventh Turkish Field Crop Congress 23-27 June, 2007; Erzurum, p. 38-41.

6. Atalay, I. 1994. Vegetation geography of Turkey. Izmir, Turkey: Ege University Publication. 352 p.

7. Koc, A., T. Oztas, and L. Tahtacioglu. 2000. Rangelandlivestock interaction in our near history problems and recommendations. Proceedings of the International Symposium on Desertification. 13-17 June, 2000, Konya, p. 293-298.

8. Atalay, I. 1997. Turkey's geography. Izmir, Turkey: Ege University Publication. 496 p.

Authors are Rangeland Scientist, University of Eskisehir Osmangazi, Eskisehir, Turkey aliko@ogu.edu.tr (Koc); Rangeland Scientist, University of Nebraska-Lincoln, Lincoln, NE 68583-0915, USA (Schacht); and Rangeland Scientist, University of Ataturk, Erzurum, Turkey (Erkovan). 